\title{
Compte rendu de Kanaky Nouvelle-Calédonie indépendante? par Patrick Castex
}

Isabelle Leblic

\section{(2) OpenEdition \\ Journals}

Édition électronique

URL : https://journals.openedition.org/jso/9730

DOI : $10.4000 /$ jso.9730

ISSN : 1760-7256

Éditeur

Société des océanistes

Édition imprimée

Date de publication : 15 décembre 2018

Pagination : 602-603

ISBN : 978-2-85430-136-6

ISSN : 0300-953x

Référence électronique

Isabelle Leblic, "Compte rendu de Kanaky Nouvelle-Calédonie indépendante ? par Patrick Castex »,

Journal de la Société des Océanistes [En ligne], 147 | 2018, mis en ligne le 15 décembre 2018, consulté le 27 septembre 2021. URL : http://journals.openedition.org/jso/9730 ; DOI : https://doi.org/10.4000/ jso. 9730

Ce document a été généré automatiquement le 27 septembre 2021.

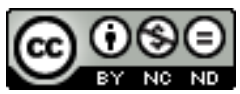

Journal de la société des océanistes est mis à disposition selon les termes de la Licence Creative Commons Attribution - Pas d'Utilisation Commerciale - Pas de Modification 4.0 International. 


\title{
Compte rendu de Kanaky Nouvelle- Calédonie indépendante? par Patrick Castex
}

\author{
Isabelle Leblic
}

\section{RÉFÉRENCE}

CASTEX Patrick, 2018. Kanaky Nouvelle-Calédonie indépendante ?, Paris, L'Harmattan, coll.

Écrit-Tic, Économie, gestion, société, 295 p., bibliogr., nombreux graphiques.

1 Parmi les nombreux ouvrages sortis en cette année référendaire, celui-ci est sans doute le plus documenté. Il comporte de nombreux graphiques (en noir et blanc dans le livre mais que l'on peut avoir en couleur, avec bien d'autres données actualisées après la sortie du livre (juin 2018, fin d'écriture le 6 juin), sur le site lié au livre de l'auteur (http://kanaky18-referendum.monsite-orange.fr/).

2 L'introduction, dont le titre « Un destin pas commun du tout » n'est pas sans évoquer la table ronde à l'université d'Hawai'i à Mānoa de 2017 (publiée dans ce volume), donne d'entrée de jeu le ton de l'ouvrage. L'auteur y retrace à grands pas l'histoire du Caillou pour arriver à la situation actuelle. Il présente son livre comme « un essai socioéconomico-politique, comme un roman à suspense particulier: comme un roman noir.» (p. 15)

« Notre objectif est de montrer que le Caillou peut être économiquement et politiquement indépendant, avec ou sans association avec la France, à condition que des réformes économiques (lutte contre les inégalités, fiscalité et régimes de sécurité sociale, stratégie minière du nickel) soient mises en œuvre.» (p. 16)

3 Ainsi, pour l'auteur, la Kanaky peut être économiquement et socialement indépendante (p. 268) et ce, malgré l'importance des transferts de la métropole (p. 270), transferts qui devront être remplacés progressivement par des prélèvements obligatoires locaux 
payés par les plus aisés (p. 271). Et, elle le sera peut-être politiquement, mais sans doute pas le 4 novembre 2018, nous dit-il sur son site.

La première, «Les contraintes sociales nées de l'histoire: inégalités et luttes ethniques,
luttes de classes» (pp.17-84), revient sur la marginalisation des Kanak dans la
mosaïque ethnique inégalitaire et la tentative d'extinction menée par le pouvoir colonial, puis sur la résilience kanak face à la domination toujours criante des Blancs, la place des autres plus proches des Blancs que de leurs frères océaniens, et les situations fort contrastées des trois provinces. Puis, dans les luttes sociales, se trouvent en premier lieu les luttes pour la récupération des terres spoliées, ce qui est articulé avec la confrontation de la société kanak à l'économie de marché, à la vie chère et aux inévitables luttes syndicales dans ce contexte.

6 La deuxième partie, « Les contraintes économiques : Kanaky Nouvelle-Calédonie seraitelle économiquement viable? » (pp. 85-190) traite le dossier sans concessions, avec une multitude de données. En partant de la situation macro-économique, l'auteur nous présente les périodisations, les cycles économiques et les équilibres ou déséquilibres structurels. Il examine ainsi minutieusement les périodisations possibles des cycles avec leurs forces et leurs faiblesses, l'évolution récente du PIB et du commerce extérieur dans le cadre des déséquilibres macro-économiques, la belle inconnue du partage des revenus entre travail et capital que l'on ne peut découvrir qu'en passant par le détour de la balance des paiements. Puis viennent les comptes publics avec un regard particulier sur le rôle des transferts financiers vers le Caillou, et la crise de 2016 qui provoque un ralentissement notable dans l'emploi salarié. Enfin, on ne peut parler d'économie calédonienne sans parler du nickel et du BTP... Si le nickel joue le rôle de locomotive, il est aussi le centre de tous les conflits de politique économique.

7 La troisième partie, «Le politique : l'éclatement des deux camps et les tentatives de consensus qui n'ont pas abouti » (pp.191-266), nous rappelle que la division gauche droite n'est pas vraiment opérante en Nouvelle-Calédonie et nous présente l'état des partis et coalitions depuis la Seconde Guerre mondiale jusqu'à ces dernières années. Puis l'auteur expose les contraintes des accords (Matignon-Oudinot plus Nouméa) et le rêve d'autres possibilités en mettant en parallèle ce que pensent l'onu, l'État et les institutions et les politiques locaux. Pour finir, il reprend la période récente, « les jours d'avant le jour d'après " (fin 2017-mars 2018) pour analyser la politique locale et les nombreuses visites des représentants de l'État français.

8 Le choix du titre de la conclusion, «Fin mal barrés!» (pp. 267-283), qui reprend le titre d'une pièce de théâtre de Jenny Briffa, s'avère judicieux, tant cette expression caractérise bien la situation des habitants du Caillou s'ils n'arrivent pas à trouver leur destin commun.

9 Cet ouvrage me paraît capital pour comprendre la réalité actuelle de la NouvelleCalédonie ainsi que la volonté de certains de voir le pays accéder à l'indépendance, seul moyen de rétablir égalité et justice sociale. À lire absolument... 